\title{
EFFECT OF HYDRATE FORMATION/DISSOCIATION ON EMULSION STABILITY USING DSC AND VISUAL TECHNIQUES
}

\author{
Jason W. Lachance, E. Dendy Sloan, Carolyn A. Koh* \\ Center for Hydrates Research \\ Colorado School of Mines, CO 80401 \\ USA
}

\begin{abstract}
The flow assurance industry is progressively moving away from avoidance of hydrate formation towards risk management. Risk management allows hydrates to form but prevents hydrates from agglomerating and forming a plug, or delays hydrate formation within the timescale of the residence time of the water in the hydrate-prone section of the flow line.

A key factor in risk management for an oil-dominated system is the stability of the emulsified water with gas hydrate formation. It is shown using Differential Scanning Calorimetry (DSC) that gas hydrate formation and dissociation has a destabilizing effect on W/O emulsions, and can even lead to a free water phase through agglomeration and coalescence of dissociated hydrate particles. Gas hydrate formation/dissociation has been shown to cause rapid hydrate agglomeration and emulsion destabilization. High asphaltene content crude oils are shown to resist hydrate destabilization of the emulsion.
\end{abstract}

Keywords: DSC, Hydrate Formation and Dissociation, Emulsions

\section{NOMENCLATURE}

$\Delta \mathrm{T}$ Subcooling from hydrate equilibrium $\left({ }^{\circ} \mathrm{C}\right)$

$\mathrm{T}_{\mathrm{s}}$ Temperature of the sample $\left({ }^{\circ} \mathrm{C}\right)$

$\mathrm{T}_{\mathrm{f}}$ Temperature of the furnace $\left({ }^{\circ} \mathrm{C}\right)$

$\mathrm{T}_{\mathrm{r}}$ Temperature of the reference $\left({ }^{\circ} \mathrm{C}\right)$

$\mu \quad$ Viscosity (cP)

${ }^{*}$ Corresponding author: E-mail: ckoh@mines.edu 


\subsection{INTRODUCTION}

Gas hydrates are crystalline clathrate compounds comprising of hydrogen bonded water lattices which encapsulate suitably sized gas molecules at high pressures and low temperatures.

Gas hydrate formation in subsea gas and oil transmission lines can block flowlines, resulting in catastrophic safety and economic problems. As gas and oil exploration and production move to ultradeep water ( $>8000$ feet of sea water), the risk of hydrate formation increases significantly [1]. Under these conditions, traditional methods of hydrate avoidance become increasingly uneconomic and ecologically unsound. Emulsion stability has been suggested to be a determining factor for hydrate agglomeration during shut-in conditions in a pipeline and also one key factor under flowing conditions $[2,3]$. One conceptual picture for hydrate formation in water-in-oil (W/O) emulsions is shown in Figure 1.

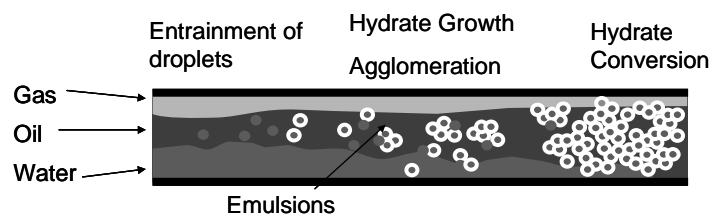

Figure 1: Conceptual picture of hydrate agglomeration and plug formation in water-in-oil emulsions in a flowing condition

The ability for the emulsified droplets to remain segregated under shut-in conditions as well as flowing conditions with hydrate formation/ dissociation is crucial to prevent hydrate plug formation.

This paper focuses on the effect of hydrates on emulsion stability, and the ability of the emulsified droplets to stay segregated with hydrate formation. The stability of water-in-oil emulsions with hydrate formation was investigated with differential scanning calorimetry (DSC), using different crude oils with varying emulsion stability.

\subsection{EXPERIMENTAL METHODOLOGY}

\subsection{Apparatus}

A high pressure micro-Differential Scanning Calorimeter ( $\mu$-DSC VIIa, Setaram Inc.) was used to measure the thermal properties of ice and hydrate in water-in-oil emulsified systems. The $\mu$ -
DSC can be used to measure properties at both atmospheric and pressurized conditions [4]. The pressure is controlled by a gas pressure panel in which a piston can be used to charge the sample with gas at pressures ranging from 1-400 bar.

The thermocouples in the calorimetric furnace measure the temperature difference between the reference and sample cells and record the heat necessary to achieve a zero temperature difference between the cells [5].

The water-in-oil emulsified samples are prepared using a Cyclone $\mathrm{IQ}^{2}$ Microprocessor Controlled Homogenizer (VirTis Co). The homogenizer has the ability to emulsify the mixture from $5000 \mathrm{rpm}$ to $30,000 \mathrm{rpm}$. The homogenizer shaft is a $10 \mathrm{~mm}$ rotor/stator shaft assembly. The emulsion characteristics depend on the preparation procedure [6] (i.e. homogenization speed, time, addition of water). For these experiments, the water was added to the oil drop-wise during the homogenization. The samples were homogenized at $8000 \mathrm{rpm}$ for 150 seconds.

\subsection{Modes of Operation}

A 10-30 mg sample was placed into the sample cell. Methane, at 150 bar, was introduced into the sample cell at $30^{\circ} \mathrm{C}$. Two different modes were used in the DSC: ramped and isothermal.

The ramped mode cooled the sample from $30^{\circ} \mathrm{C}$ to $-45^{\circ} \mathrm{C}$ at $0.5^{\circ} \mathrm{C} / \mathrm{min}$. The sample temperature was then increased back to $30^{\circ} \mathrm{C}$. This cooling-heating cycle was repeated three times to observe the effects of ice/hydrate on the emulsions.

The isothermal mode cooled the sample from $30^{\circ} \mathrm{C}$ to $-10^{\circ} \mathrm{C}$. The sample was held at this temperature for approximately six hours. Upon hydrate formation, the sample was heated to dissociate the hydrate. The runs were repeated two times to observe the effect of hydrate on the emulsions (no ice formation was observed in these runs).

\subsection{Materials}

The oils that were used in this study are listed below in Table 1. 
Table 1: Crude oil properties

\begin{tabular}{lcccc}
\hline Crude & $\begin{array}{l}\text { Viscosity } \\
\text { (cP) }\end{array}$ & $\begin{array}{c}\text { Asph. } \\
\text { (wt\%) }\end{array}$ & $\begin{array}{c}\text { Resin } \\
\text { (wt\%) }\end{array}$ & TAN \\
\hline Crude A* $^{*} 247$ & 7.12 & 9.36 & N/A \\
Crude B $^{* *}$ & 220 & 6.2 & 20.5 & 0.7 \\
Crude C** $^{*} 147$ & 4.6 & 9.9 & 0.3 \\
Crude D** $^{*}$ & 20 & 3.3 & 11.2 & 2.5 \\
\hline
\end{tabular}

*Measurements by Baseline DGSI Analytical Laboratories (SARA)

**Measurements by Norwegian University of Science and Technology (SARA)

The emulsion stability was measured using the DSC over a one month time period using the procedure outlined by Clausse 2006 [7].

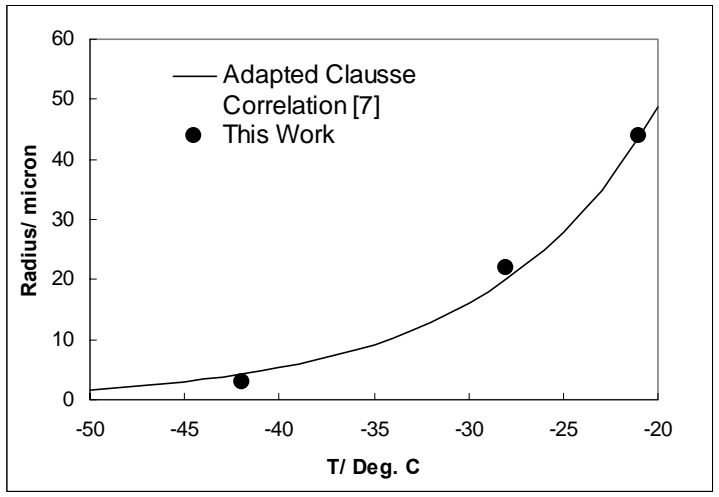

Figure 2: Radius of water droplets versus ice nucleation temperature[7]. Dots are measurements performed in this laboratory [8]

Figure 2 shows that larger droplets nucleate at higher temperatures compared to smaller droplets $[7,9]$. This provided the basis for determining emulsion destabilization in our crude oils. As an emulsion was destabilized, the droplets coalesced to form larger droplets compared to the droplets in the original, stable emulsion. Figure 3 shows an example emulsion stability test in Crude A.

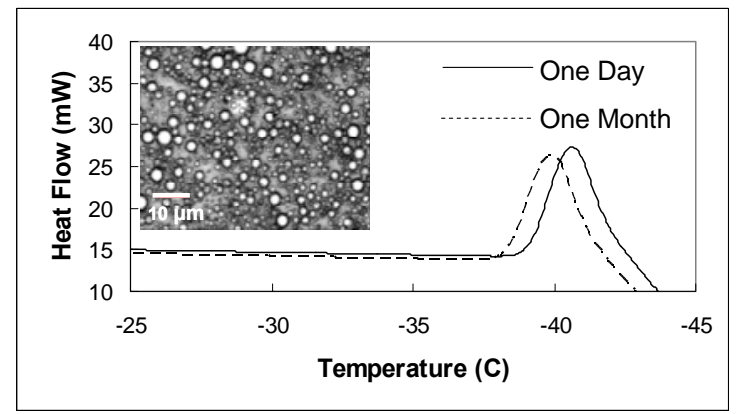

Figure 3: Emulsion stability test of Crude A. Thermograms for emulsions after 1 day and after one month time. Inset: Microscope image of the water-in-oil emulsion aged for 1 day
After ageing the emulsion for 1 month, the ice nucleation peak shifted to higher temperatures compared to the 1 day emulsion, indicating coalescence/emulsion destabilization. The shift in the ice nucleation peak by less than $1^{\circ} \mathrm{C}$ in Crude $\mathrm{A}$ indicates that this crude is very stable. Additionally, using the Clausse correlation, the droplet size in Crude A is less than 10 microns. This is in agreement with the microscopic image (inset in Figure 3). Table 2 shows the results of the emulsion stability tests for all of the crude oils in this study.

Table 2: Emulsion stability of crude oils using DSC. $\Delta \mathrm{T}=\mathrm{T}(1$ day $)-\mathrm{T}(1$ month $)$

\begin{tabular}{cccc}
\hline Crude & $\boldsymbol{\Delta} \mathbf{T}^{\circ} \mathbf{C}$ & Stability & Drop Size $(\boldsymbol{\mu m})$ \\
\hline Crude A & 0.6 & High & $<10$ \\
Crude B & 0.9 & High & $<10$ \\
Crude C & 1.2 & High & $<10$ \\
Crude D & 7.2 & Moderate & $5-25$ \\
\hline
\end{tabular}

Crude A, Crude B, and Crude C form stable emulsions, while Crude D showed moderate destabilization in the one month time period. No free water phase was observed with these crude oils in the one month time period.

HPLC water (Aldrich Inc.) was used in these studies at a concentration of $30 \mathrm{wt} \%$ in oil. Hydrates were formed using methane $(99.99 \%$ purity, AirGas) at $150 \mathrm{bar}\left(\mathrm{T}_{\text {diss. }}=16.3^{\circ} \mathrm{C}[10]\right)$.

\subsection{RESULTS AND DISCUSSION 3.1 Comparison of ice and hydrate formation on emulsion stability}

Initially, the ramped mode was used in the DSC to measure the effects of ice and hydrate on the emulsion stability. Figure 4 shows a thermogram of multiple ice formation runs in Crude A.

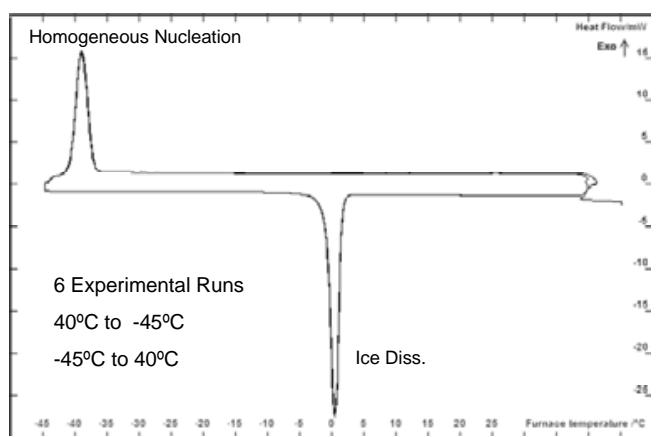

Figure 4: Effect of ice formation on emulsion characteristics after six consecutive runs in the DSC in Crude A 
Figure 4 shows that six consecutive runs are superimposed on each other; the ice formation peak did not shift indicating that the emulsion was not altered by the ice formation. However, using the same procedure, hydrate formation was found to be much more effective at destabilizing the emulsion in Crude A as shown in Figure 5A.

The first run shows only hydrate formation (broad peak); Figure 5A; however, the second and third runs show an increased amount of ice formation as indicated by the sharp peaks. These peaks can be attributed to ice by observing the dissociation trends upon heating the sample as shown in Figure $5 \mathrm{~B}$. Figure $5 \mathrm{~B}$ verifies that ice formed as indicated by the peak at $0^{\circ} \mathrm{C}$. The addition of hydrate to the system in the first run caused the emulsion to destabilize, and water droplets to coalesce to larger droplets.

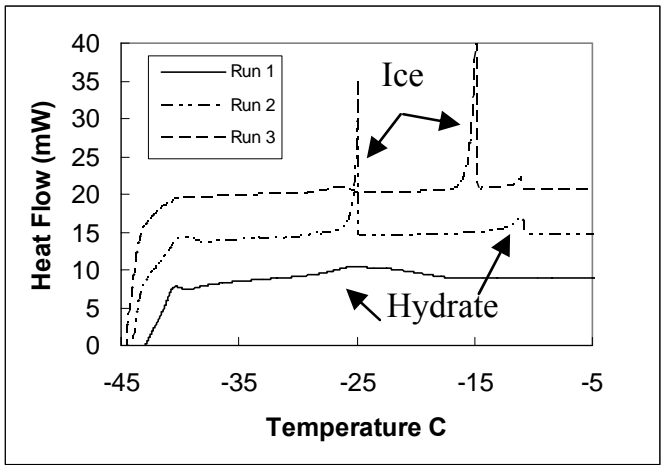

(A)

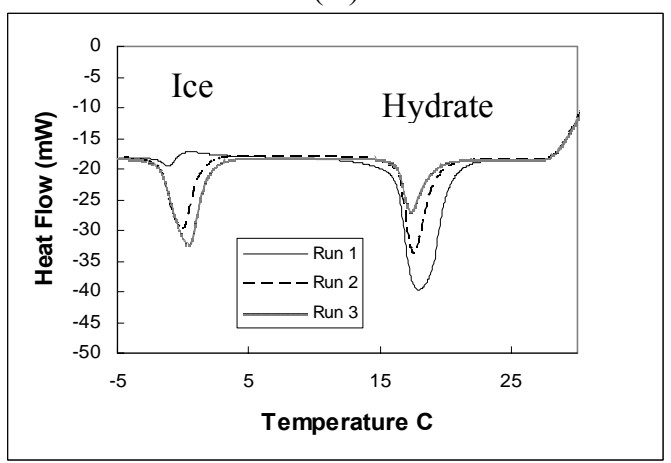

(B)

Figure 5: Hydrate formation (A) and hydrate/ice dissociation (B) in water-in-Crude A using successive ramped runs in DSC

The first observation of this destabilization was shown by Palermo et al. [10] conceptually in Figure 6 to explain agglomeration tendencies in crude oils.

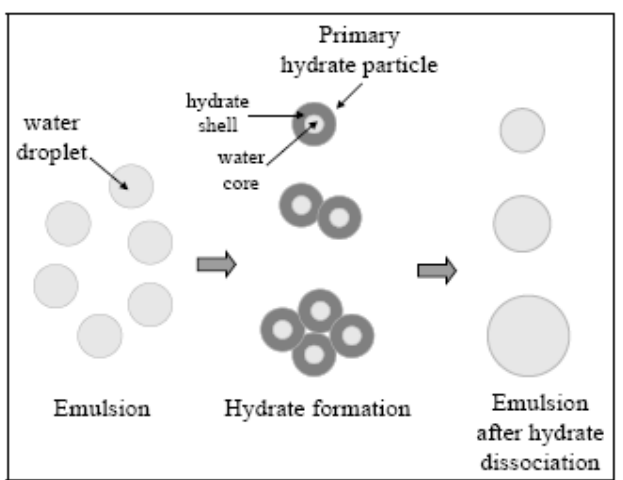

Figure 6: Mechanism for hydrate agglomeration in the DSC after successive runs [11]

The model shows that once hydrates agglomerate, upon dissociation the droplets will come together to form a larger droplet. Therefore on the next hydrate formation run, the loss of surface area will reduce the hydrate formation producing the trends observed in Figure 5B.

The enlargement of the droplets was observed in Figure $5 \mathrm{~A}$ by the sharp ice nucleation peaks at $25^{\circ} \mathrm{C}$ which corresponded to an increase in droplet size to 30-40 microns in the second run compared to 10 microns initially. The first run formed only hydrate so this increase in droplet size is caused by hydrate formation/dissociation. The ice nucleation peak was shifted to higher temperature, with increased droplet size, on the third run, indicating further destabilization.

This destabilization by hydrate was also observed visually using water-in-cyclopentane/Crude B atmospheric hydrates as shown in Figure 7.

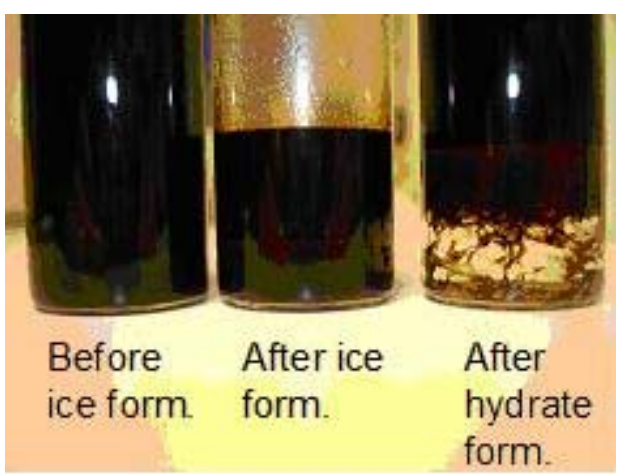

Figure 7: Effect of hydrate and ice formation on the emulsion stability of a water-in-cyclopentane/Crude B system 
The ice did not destabilize the emulsion whereas the hydrate destabilized the emulsion to a greater extent, causing a free water phase to be present. These results provide visual confirmation of the results obtained by the DSC in Figure 5.

Lin et al. [12] showed that ice formation is a common method to destabilize emulsions due to expansion of the water droplets. Hydrates thermal expansivity is 1.3 times greater than ice [1] which could enhance the effectiveness of hydrates in destabilizing emulsions.

\subsection{Effect of emulsion stability on hydrate formation/dissociation trends}

The DSC was used to form hydrate at $-10^{\circ} \mathrm{C}$ isothermally without the formation of ice. The dissociation trends for Crude $\mathrm{A}$ are shown in Figure 8 .

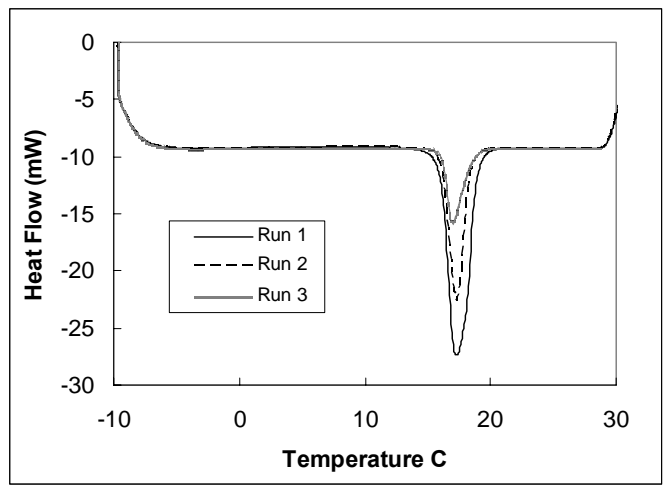

Figure 8: Hydrate dissociation trends after three consecutive isothermal hydrate formation runs in Crude A

Interestingly, the trends in the isothermal runs without ice formation show identical trends to the ramped runs with ice formation. The trends for Crude A show a moderate destabilization. However, the Crude D showed significant destabilization in only two consecutive runs as shown in Figure 9.

The Crude D run 2 dissociation peak is decreased more than three consecutive runs with Crude A. This indicates that the hydrates destabilized the emulsion much faster in Crude D.

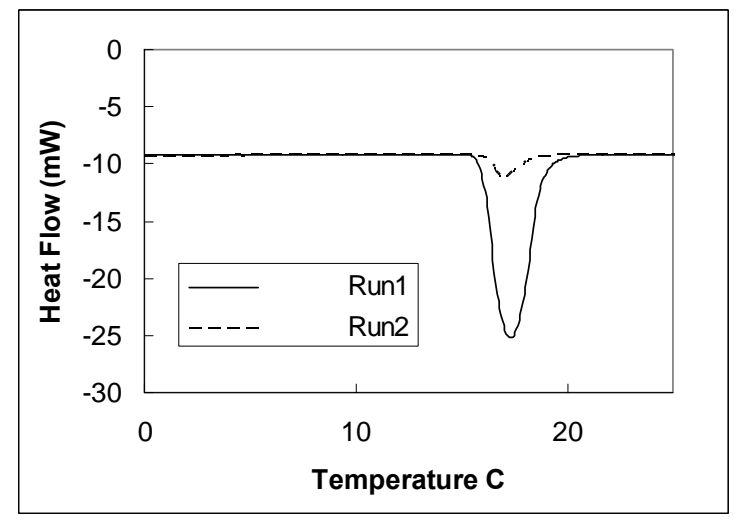

Figure 9: Hydrate dissociation trends in a water-inCrude D emulsion after two consecutive isothermal runs

Table 3 shows the reduction of hydrate after two consecutive isothermal runs for the crude oils in this study. The loss of hydrate was calculated by comparing the second hydrate dissociation peak by the first hydrate dissociation peak. This reduction of hydrate is caused by the decrease in surface area due to the hydrate-induced destabilization as shown in Figure 6.

Table 3: Loss of hydrate after two consecutive runs

\begin{tabular}{ccc}
\hline Crude & Loss of Hydrate (\%) & Stability \\
\hline Crude A & 22.3 & Moderate \\
Crude C & 26.2 & Moderate \\
Crude B & 55.7 & Low \\
Crude D & 87.6 & Low \\
\hline
\end{tabular}

Table 3 shows that the emulsions with higher stability were most stable in the presence of hydrate, as indicated by the lower reduction in hydrate formation.

The results also suggest that Crude A with the higher content of asphaltenes resisted destabilization due to hydrate formation/dissociation. However, the effect of other surface active components, such as resins and acids, on asphaltene deposition at the interface also played a role in these findings. Crude B has a higher concentration of asphaltenes compared with Crude C; however, Crude B also has a very high concentration of resins which may block the deposition of asphaltenes onto the water droplet interface [13]. Additionally, Crude C and Crude D have similar amounts of asphaltenes, but the Crude $\mathrm{D}$ has a higher acid number which has been shown to decrease emulsion stability thus Crude D did not resist hydrate destabilization [14]. 
These experiments indicate that the asphaltene fraction in crude oils resisted destabilization caused by hydrates. McLean et al. [12] have also shown that asphaltenes are the dominant fraction in crude oils that resist emulsion destabilization without hydrates.

\subsection{CONCLUSIONS}

The results from this study show the hydrate formation/dissociation is effective at destabilizing emulsions. The asphaltene fraction of crude oils is shown to resist hydrate-induced destabilization.

As asphaltene content increases, emulsion stability also increases which suggests that emulsion stability is one key factor in preventing agglomeration in a flow line.

\section{ACKNOWLEDGEMENTS}

The authors wish to acknowledge the financial support received from the CSM Hydrate Consortium and the Deepstar consortium of energy companies.

\section{REFERENCES}

[1] Sloan, E. D. and Koh, C.A. Clathrate Hydrates of Natural Gases, 3rd Edition, Taylor and Francis, CRC Press. 2008.

[2] Fadnes F. Natural Hydrate Inhibiting Components in Crude Oil. Fluid Phase Equilibria. 1996. 117; 186-192.

[3] P. Hemmingsen, X. Li, J.L. Peytavy, J. Sjoblom, Dispersion Science. 28 (2007).

[4] Setaram. Micro DSC VII Commissioning Utilisations. 2003

[5] Sorai. Comprehensive Handbook of Calorimetry and Thermal Analysis. Maruzen Company Limited. 1998.

[6] Salager J. Emulsion Formulation Seminar. Center for Hydrate Research. Golden, CO, September 23. 2007.

[7] Clausse D., Gomez F., I. Pezron, L. Komunjer, C. Dalmazzone, Morphology characterization of emulsions by differential scanning calorimetry. Advances in Colloid and Interface Science. 2005

[8] Lachance J. Investigation of Gas Hydrates using Differential Scanning Calorimetry with Water-in-Oil Emulsions. Colorado School of Mines, Masters. 2008.

[9] Angell, C. A. (1999). "Biography." Journal of Physical Chemistry B 103: 3977-2978.

[10] Ballard, A. A Non-Ideal Hydrate Solid Solution Model For A Multi-Phase Equilibria Program. Chemical Engineering, Colorado School of Mines. Ph. D. 2001.

[11] Palermo T., Arla D., M. Borregales, C. Dalmazzone, L. Rousseau, Study of the agglomeration between hydrate particles in oil using differential scanning calorimetry (DSC). Proceedings of Fifth International Conference on Gas Hydrates Volume 1. Kinetics and Transport Phenomena: 332339. 2005

[12] Lin, C., He, G., X. Li, L. Peng, C. Dong, $\mathrm{S}$. Gu, G. Xiao, Freeze/Thaw induced demulsification of water-in-oil emulsions with loosely packed droplets. Separation and Purification Technology doi:10.1016/j.seppur.2007.01.035. 2007.

[13] McLean J., Spiecker P., A. Sullivan, P. Kilpatrick, Structure and Dynamics of Asphaltenes. New York, Palium Press. 1998.

[14] Hemmingsen P., Kim S., H. Pettersen, R. Rodgers, J. Sjoblom, A. Marshall, Structural Characterization and Interfacial Behavior of Acidic Compounds Extracted from a North Sea Oil. Energy and Fuels 20: 1980-1987. 2006. 